\title{
Cladistics
}

\section{Molecular phylogenetics of an aquatic plant lineage, Potamogetonaceae}

\author{
Charlotte Lindqvist ${ }^{1, *}$, Jan De Laet ${ }^{2}$, Robert R. Haynes ${ }^{3}$, Lone Aagesen ${ }^{4}$, \\ Brian R. Keener ${ }^{3,5}$ and Victor A. Albert ${ }^{1}$ \\ ${ }^{1}$ Natural History Museum, University of Oslo, PO Box 1172 Blindern, 0318 Oslo, Norway; ${ }^{2}$ Leuvenstraat 20, B-3020 Veltem-Beisem, Belgium; \\ ${ }^{3}$ Department of Biological Sciences, University of Alabama, Tuscaloosa, AL 35487, USA; ${ }^{4}$ Instituto de Botánica Darwinion, C.C. 22, 1642 San Isidro, \\ Argentina; ${ }^{5}$ Department of Biological and Environmental Sciences, University of West Alabama, Livingston, AL 35470, USA
}

Accepted 7 June 2006

\begin{abstract}
Like most aquatic plants, the pondweeds (Potamogetonaceae) are among the most phenotypically reduced and plastic of all angiosperms. As such, hypotheses of structural homology present difficulties for morphological phylogenetic reconstruction. We used non-coding nuclear and plastid DNA data to address Potamogetonaceae relationships and accompanying issues in character evolution and biogeography. Genera currently assigned to Potamogetonaceae, plus Zannichellia, formed a strongly supported monophyletic group. Potamogeton and Stuckenia (Potamogeton subg. Coleogeton) were both resolved as monophyletic. Within Potamogeton proper, two major clades followed the traditional split between broad- and narrow-leaved species, with the latter condition optimized as basal. Heterophylly (submerged plus floating leaves) has evolved several times, and the ancestral distribution for Potamogeton appears to be Northern Hemispheric. Our phylogenetic results have provided a useful genetic framework from which to interpret morphological, cytological and biogeographical evolution.

(C) The Willi Hennig Society 2006.
\end{abstract}

Aquatic plants exhibit striking morphological diversity despite constituting only a relatively small fraction of angiosperms (less than 2\%; Cook, 1990). They are characterized by extreme morphological reductions, both losses of features that are assumed to be otherwise adaptive to terrestrial life, and repeated gains among unrelated species of attributes perceived as adaptive for the aquatic habitat (Arber, 1920; Sculthorpe, 1967). Furthermore, extensive phenotypic plasticity, which is largely influenced environmentally as opposed to genetically, is commonplace among aquatic plants. The challenges these attributes pose for general evolutionary hypothesis construction and for the classification of aquatic plants were recognized early by Arber (1920; see

*Corresponding author:

E-mail address: charlotte.lindqvist@nhm.uio.no also Sculthorpe, 1967; Barrett et al., 1993). Problems with homology assessments of traits associated with aquatic life, which may convergently define specialized characters or extensive phenotypic plasticity that is not genetically based, have presented a great challenge when attempting phylogenetic inferences (Les and Haynes, 1995).

The pondweeds, Potamogeton L. (Potamogetonaceae), represent one of the most important plant genera in the aquatic environment, especially as food or habitat for aquatic animals (Haynes, 1974). Studies have also shown some species to be important in stabilizing substrates, removing particulate matter from the water column, and as indicators for water quality (e.g., Dierberg et al., 2002; Fritioff and Greger, 2003). This cosmopolitan genus, which is generally thought to comprise approximately 80-100 species, displays heterophylly both between and within species. Furthermore, 
several species exhibit extensive growth phase, seasonal, and geographic morphological plasticity. Hybridization is thought to be relatively frequent, and complex series of (even infraspecific) polyploidy and aneuploidy are present within the genus (e.g., Haynes, 1974, 1978; Les, 1983; Wiegleb, 1988; Hollingsworth et al., 1998; Kaplan, 2002; Fant et al., 2003). Consequently, Potamogeton has been considered to be taxonomically difficult, and the large number of known phenotypes has historically led taxonomists to create a complex infrageneric classification with varying numbers of subsections and infraspecific taxa, which has resulted in considerable nomenclatural confusion. Traditionally, Potamogeton has been separated into two subgenera (Raunkiær, 1896), although recent suggestions have been made to elevate subgenus Coleogeton (Rchb.) D.H.Les \& R.R.Haynes to the generic level, giving it the correct name Stuckenia Börner (Les and Haynes, 1996; Holub, 1997; Haynes et al., 1998). Within subgenus Potamogeton, two morphological groups have been recognized, the broad-leaved species and the linearleaved species (Fernald, 1932; Ogden, 1943), although it has been questioned if these groupings represent monophyletic entities (Les, 1983).

Potamogeton (including Stuckenia) belongs to the family Potamogetonaceae, which as currently circumscribed also includes the monotypic genus Groenlandia J.Gay. The delimitation of Potamogetonaceae and assumed allies has, however, changed throughout history: e.g., the family has included the genus Ruppia L., and members of the family have been placed in the Najadaceae and have even been combined with members of Zannichelliaceae and Zosteraceae (also see Haynes, 1978 and references therein; Les and Haynes, 1995). Furthermore, various hypotheses as to the position of Potamogetonaceae within the largely aquatic subclass Alismatidae (Alismatales sensu Angiosperm Phylogeny Group, 2003) have been suggested, highlighting the problems of systematic studies of aquatic plants based on morphological data (Les and Haynes, 1995).

Few molecular phylogenetic studies of Potamogetonaceae and relatives have been published, of which only the work by Les and coworkers (Les et al., 1993; Les and Haynes, 1995; Les et al., 1997) has included sufficient taxa to provide valuable insight into phylogenetic relationships within Alismatidae. Based on $r b c L$ sequence data representing all recognized families and $83 \%$ of the genera, Potamogetonaceae was placed in a derived position within the subclass, together with members of Zannichelliaceae, in a strongly supported clade sister to Zosteraceae (Les et al., 1997). However, the $r b c L$ sequences provided poor phylogenetic resolution within this lineage and only few taxa of Potamogetonaceae were included. Therefore, although the overall position of Potamogetonaceae within
Alismatidae seems relatively unambiguous, family and generic level relationships are still left incomplete.

Our principal purpose with the present study is to ascertain major infrageneric groupings and phylogenetic relationships within Potamogeton sensu stricto. A small but relevant study among Potamogeton species was recently published (Iida et al., 2004), but the sampling was restricted to Japanese taxa. Although North American taxa are emphasized in our present study, we have included a large number of taxa from outside this area since we wanted to address not only gross morphological evolutionary patterns in Potamogeton but also biogeographical relationships. In addition, we wished to evaluate: (1) higher-order relationships to other Alismatidae; (2) the phylogenetic position of Potamogeton within Potamogetonaceae; and (3) the monophyly of taxa assigned to Stuckenia and their position within or outside Potamogeton.

To investigate phylogenetic relationships on the infrageneric level, we analyzed variation within the rapidly evolving non-transcribed spacer of the $5 \mathrm{~S}$ nuclear ribosomal array (5S-NTS), which has been used for a number of molecular phylogenetic and specieslevel studies in plants (Cox et al., 1992; see Lindqvist et al., 2003). In order to address interrelationships among the members assigned to Potamogetonaceae, we used the non-coding chloroplast DNA regions, $\operatorname{trn} L$ intron and $p s b A$-trnH spacer (Taberlet et al., 1991; Sang et al., 1997).

\section{Materials and methods}

\section{Plant material}

Most Potamogetonaceae accessions used in this study were obtained from herbarium material held at the University of Alabama. One Groenlandia accession and all other outgroup taxa included were obtained from either herbarium material held at University of Oslo or fresh material grown in the Botanical Garden at the Natural History Museum, University of Oslo. Included in the study were extracted DNAs from herbarium and fresh, silica-dried material from a total of 70 accessions representing 58 accessions of Potamogeton, eight of Stuckenia, two of the monotypic Groenlandia densa, and two of Zannichellia L. (see Table 1). In the 5S-NTS study, 57 Potamogeton accessions representing 44 species, six Stuckenia accessions representing four species, as well as one accession each of Groenlandia densa and Zannichellia were included. In the $p s b A$-trn $H$ spacer analysis, 41 Potamogeton sequences representing 33 species, three Stuckenia species, and one accession each of Groenlandia and Zannichellia were used. Of trnL intron sequences, 23 Potamogeton accessions representing 20 species, four Stuckenia species, two Zannichellia 
species, and one Groenlandia accession were included. In order to investigate intergeneric phylogenetic relationships among Potamogeton, Groenlandia, Stuckenia and Zannichellia, we attempted to isolate DNAs and determine psbA-trnH spacer and trnL intron cpDNA sequences for several putative outgroup alismatid taxa. Sequences from the following genera were successful: Butomus L., Echinodorus Rich. ex Engelm., Ruppia, Sagittaria L., Scheuchzeria L., Triglochin L., Zostera L. as well as the arid genus Alocasia (Schott) G. Don. Furthermore, trnL intron sequences from Magnolia L., Orontium L., and Tofieldia Huds. were obtained from GenBank, NCBI. See also Table 1 for a listing of the accessions and their voucher information.

\section{Molecular methods}

Dried leaf tissue was in most cases ground using the FastPrep instrument (Qbiogene, Carlsbad, CA) and DNA extracted as described in Lindqvist and Albert (2002). In case of the outgroup taxa, tissue was ground using a Mixer Mill MM 301 (Retsch GmbH \& Co. KG, Haan, Germany) and the DNA was isolated using the DNeasy Plant Mini kit (Qiagen, Valencia, CA) following the manufacturer's instructions. Polymerase chain reaction (PCR) amplifications and automated DNA sequencing were performed as described in Lindqvist and Albert (2002). The 5S-NTS region was amplified using the primers PI and PII described by Cox et al. (1992) and the following program: hold $94{ }^{\circ} \mathrm{C} 2 \mathrm{~min}$; 27 cycles of $94{ }^{\circ} \mathrm{C} 1 \mathrm{~min}, 60^{\circ} \mathrm{C} 1 \mathrm{~min}, 72{ }^{\circ} \mathrm{C} 1 \mathrm{~min}$; extend $72{ }^{\circ} \mathrm{C} 4 \mathrm{~min}$. The $\operatorname{trnL}$ intron was amplified using primers "c" and "d" of Taberlet et al. (1991), and the $p s b A$-trn $H$ region was amplified using the primers $p s b A \mathrm{~F}$ and trnHR of Sang et al. (1997). The same primers were used for sequencing. Forward and reverse sequences were edited and aligned for each accession and each locus using the software program Sequencher, version 3.1 (GeneCodes, Ann Arbor, MI), and the consensus sequences were deposited in GenBank, NCBI (see Table 1).

\section{Phylogenetic analyses}

Instead of performing a priori multiple alignments, we optimized nucleotide sequences directly on to trees, an approach first described by D. Sankoff in 1975 and further developed by, a.o., W. Wheeler (e.g., Wheeler, 1996; Wheeler, 2003; Wheeler, 2005). A major practical problem with the algorithm of Sankoff (1975) and other exact algorithms to determine the length of a sequence character on a given tree is their computational complexity. A direct consequence is that for most real-world data sets, heuristic approximations of these algorithms have to be applied. So, in addition to heuristics to explore tree space (such as branch swapping, ratcheting, drifting; see, e.g., Goloboff, 1999; Nixon, 1999), the generalized tree alignment problem requires an additional level of heuristics to explore, for any tree to be examined, the space of all its possible tree alignments. Examples of such heuristic algorithms to calculate the length of a sequence character on a given tree are, e.g., lifted alignments (Jiang and Lawler, 1994; see also Wheeler, 1999) or Wheeler's (Wheeler, 1996) algorithm for optimization alignment.

We analyzed our data using POY (Wheeler et al., 2003), a computer program that offers and integrates several heuristics at both levels (see De Laet and Wheeler, 2003). In all analyses, we used optimization alignment (Wheeler, 1996) as tree alignment heuristic. The basic tree search strategy, embedded in a jackknifing approach, consisted of building initial trees using a random addition sequence of taxa, followed by SPR branch swapping. The cost regime used was substitution 2, gap opening 3, and gap extension 1 (see detailed justification in De Laet, 2005b; Giannini and Simmons, 2005).

Evidential support for our results was assessed through jackknife analysis (Farris et al., 1996), a statistical resampling method that aims to identify groups that are well supported by the data. This approximation strategy is equivalent in its aim to that of Farris et al. (1996), which similarly uses parsimony as its optimality criterion. We performed a jackknife analysis (Farris et al., 1996) as adapted by De Laet (2005b) for use in Sankoff (1975) style analyses: pseudoreplicates are generated by randomly turning $37 \%$ of the nucleotides of the observed sequences into "N", indicating the presence of a further unspecified base. This was done using the program $(G)$ oechel (De Laet, 2005a). The resulting pseudoreplicates were analyzed using POY. Two approaches were used to summarize the results of the jackknife analysis: (1) construction of a majority rule consensus tree of the strict consensus trees of the individual pseudoreplicates, as in Farris et al. (1996), and (2) construction of a frequency difference consensus tree (Goloboff et al., 2003) of the strict consensus trees of the individual pseudoreplicates. In both cases, this was done using TNT (Goloboff et al., 2002). For the majority rule consensus trees, all groups exceeding $50 \%$ are shown; for the frequency difference trees, a cutoff value of $25 \%$ was used. The difference between these two approaches for summarizing the jackknife is best explained using a simple example. Assume a jackknife analysis in which 100 pseudoreplicates have been performed and consider the resulting 100 strict consensus trees. Next assume that a particular clade A occurs in 55 of those trees. Using the majority rule way of summarizing jackknifing results, clade $\mathrm{A}$ gets a jackknife support value of 55 . Using the frequency difference way, the support value for clade A depends on the 
structure of the 45 trees that do not display that clade. In the worst case, all 45 could display a same clade B that contradicts A. The support for A would then become $55-45=10$. Using a cutoff of 50 , clade A would be considered unsupported. This correctly reflects that the difference in support (as measured by the frequency in the jackknife profile) for the best hypothesis (clade A) and its runner-up (clade B) is small indeed. At the other extreme, all 45 would display a clade that contradicts clade A, but this contradicting clade would in each case be a different one. In this case, the frequency of the second best hypothesis would be only 1 out of 100 , and the frequency difference between the best hypothesis and its runner-up $55-1=54$. Still using 50 as a cutoff, clade A will now be considered as slightly supported by the data.

\section{Simultaneous optimization and jackknife analyses}

Phylogenetic analyses were executed of: (1) the 5S-NTS data alone; (2) the chloroplast data combined; and (3) all available (cpDNA and 5S-NTS) data combined. Within each of these basic data sets, no orthologous subsequences were indicated a priori.

For data set 1, 100 pseudoreplicates were analyzed, whereas 50 pseudoreplicates were performed for data sets 2 and 3. The resampled data sets (pseudoreplicates) and POY scripts to analyze these were generated through $(G)$ oechel (De Laet, 2005a) using seeds $1 \ldots$ 100 (or $1 \ldots 50$ ) and exclusion percentage 37 (after Farris et al., 1996). Each pseudoreplicate was analyzed using two replicates of initial tree creation by means of a random addition sequence of taxa, followed by SPR branch swapping. Next, the strict consensus of the best trees over the two replicates was calculated, using $(G)$ oechel. Finally, the consensus trees of all individual pseudoreplicates were used as input trees for the summary via the majority rule or frequency difference approaches in TNT (Goloboff et al., 2002). Exemplar scripts for data set 1, pseudoreplicate 100

POY (first replicate for pseudoreplicate 100)

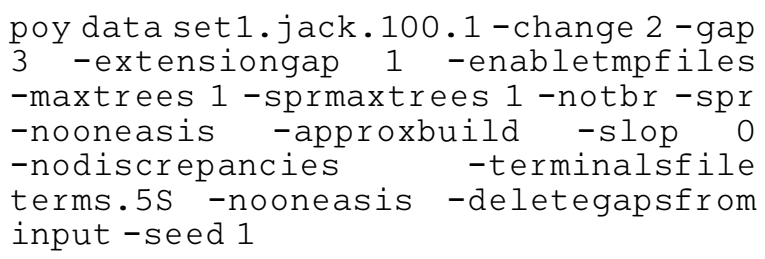

POY (second replicate for pseudoreplicate 100)

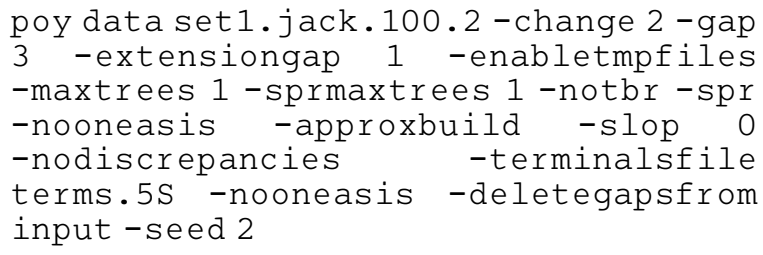

Character-state optimizations

Geographical and morphological character state optimizations were performed using WinClada (Nixon, 2002). Optimizations were performed directly on jackknife consensus trees, as these were the only tree output available using our approximation method. Of course, optimizations on trees that are not most-parsimonious (or even soft-polytomous most-parsimonious trees) may themselves not be most parsimonious, but our intention with these was to provide suggestive character-state trends for groups that are arguably well-supported by our approximate tree-search method. Data were treated as non-additive or additive (leaf width), and unambiguous character-state optimizations are reported for the majority rule jackknife tree since this tree was less resolved than the frequency difference tree (see Fig. 2) and therefore gave a more conservative estimate.

\section{Results}

\section{Sequence data}

The 5S-NTS sequence data matrix comprised a total of 66 taxa. The lengths of the DNA sequences varied in Potamogeton from $281 \mathrm{bp}$ (P. tricarinatus) to $315 \mathrm{bp}$ (P. epihydrus), in Stuckenia they varied from $273 \mathrm{bp}$ ( $S$. vaginata) to $284 \mathrm{bp}$ (S. pectinata), and the Groenlandia and Zannichellia sequences were 340 and $271 \mathrm{bp}$ long, respectively. Using direct sequencing, only very few intraindividual polymorphic sites were found, and these seemed to appear in a random phylogenetic pattern as opposed to representing, e.g., paralogs. Therefore, no effort was made to clone individual repeat elements to assess their diversity.

The $p s b A$-trnH spacer sequence data matrix comprised 55 taxa. The lengths of the sequences varied in Potamogeton from $324 \mathrm{bp}$ ( $P$. ochreatus) to $420 \mathrm{bp}$ ( $P$. robbinsii), and in Stuckenia from 356 bp $(S$. pectinata) to $395 \mathrm{bp}$ ( $S$. striata). Among the outgroup taxa the lengths varied from $384 \mathrm{bp}$ in Triglochin maritima to 579 bp on Alocasia odora.

The $\operatorname{trn} L$ intron sequence data matrix comprised 39 taxa. The lengths of the sequences varied in Potamogeton from $486 \mathrm{bp}(P$. lucens) to $563 \mathrm{bp}(P$. diversifolius and $P$. spirillus), and in Stuckenia from 558 bp ( $S$. vaginata and S. filiformis) to $576 \mathrm{bp}$ (S. striata). Among the outgroup taxa, the lengths varied from $480 \mathrm{bp}$ in Magnolia sieboldii to 745 bp in Echinodorus muricatus.

\section{Phylogenetic analyses of chloroplast DNA data}

The $\operatorname{trn} L$ intron and $p s b A$-trnH spacer regions were not analyzed separately but were combined into one "plastid DNA" data matrix, which comprised 61 taxa. Of the 61 accessions included, 27 were non-overlapping 


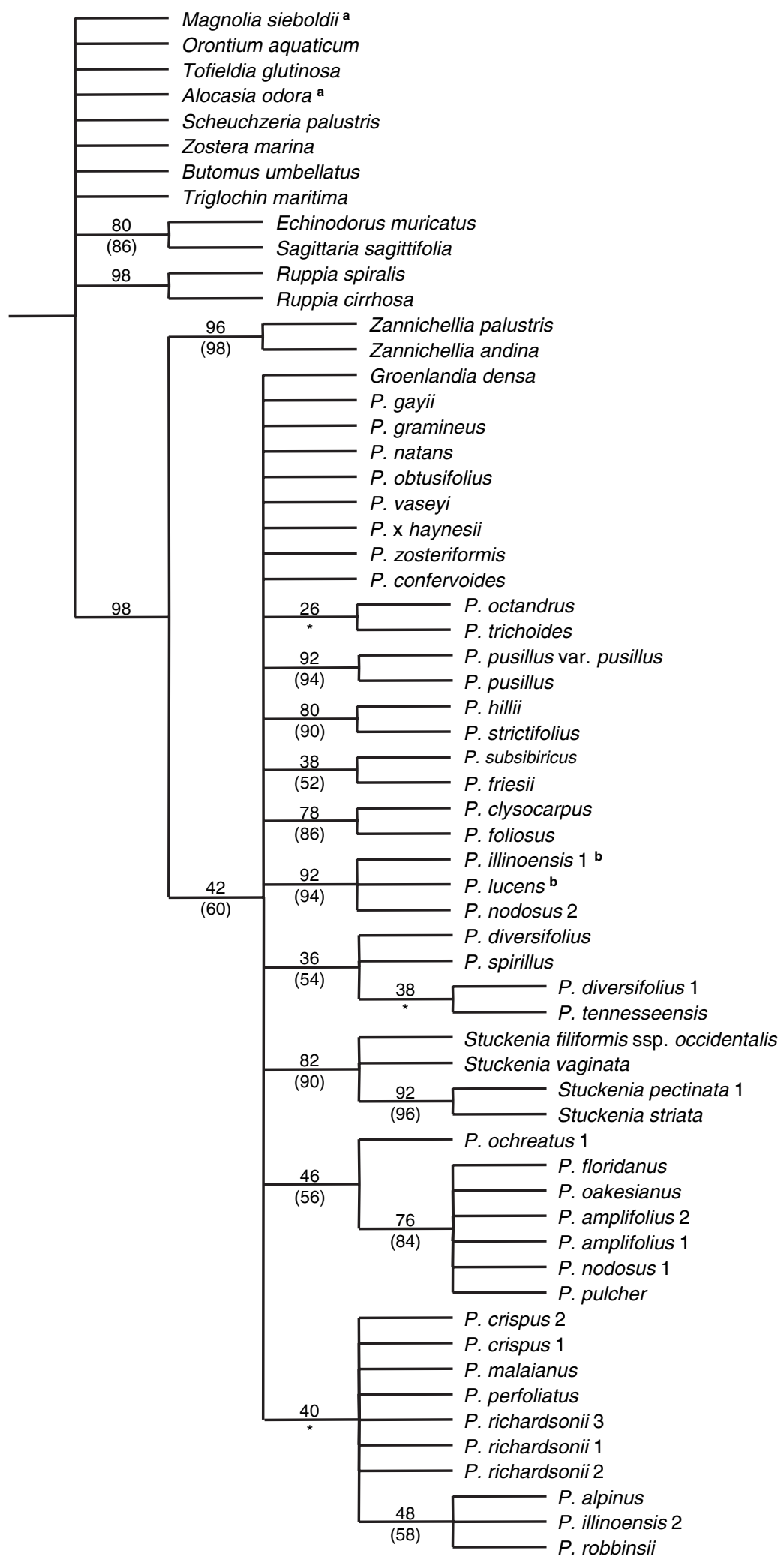

Fig. 1. cpDNA combined frequency difference jackknife consensus tree. Frequency difference jackknife support values shown above branches, and majority rule jackknife support values shown in parentheses below branches if different from frequency difference tree ( ${ }^{\mathrm{a}}$ supported at $54 \%$, ${ }^{b}$ supported at $52 \%$, *node collapsed in majority rule tree). 


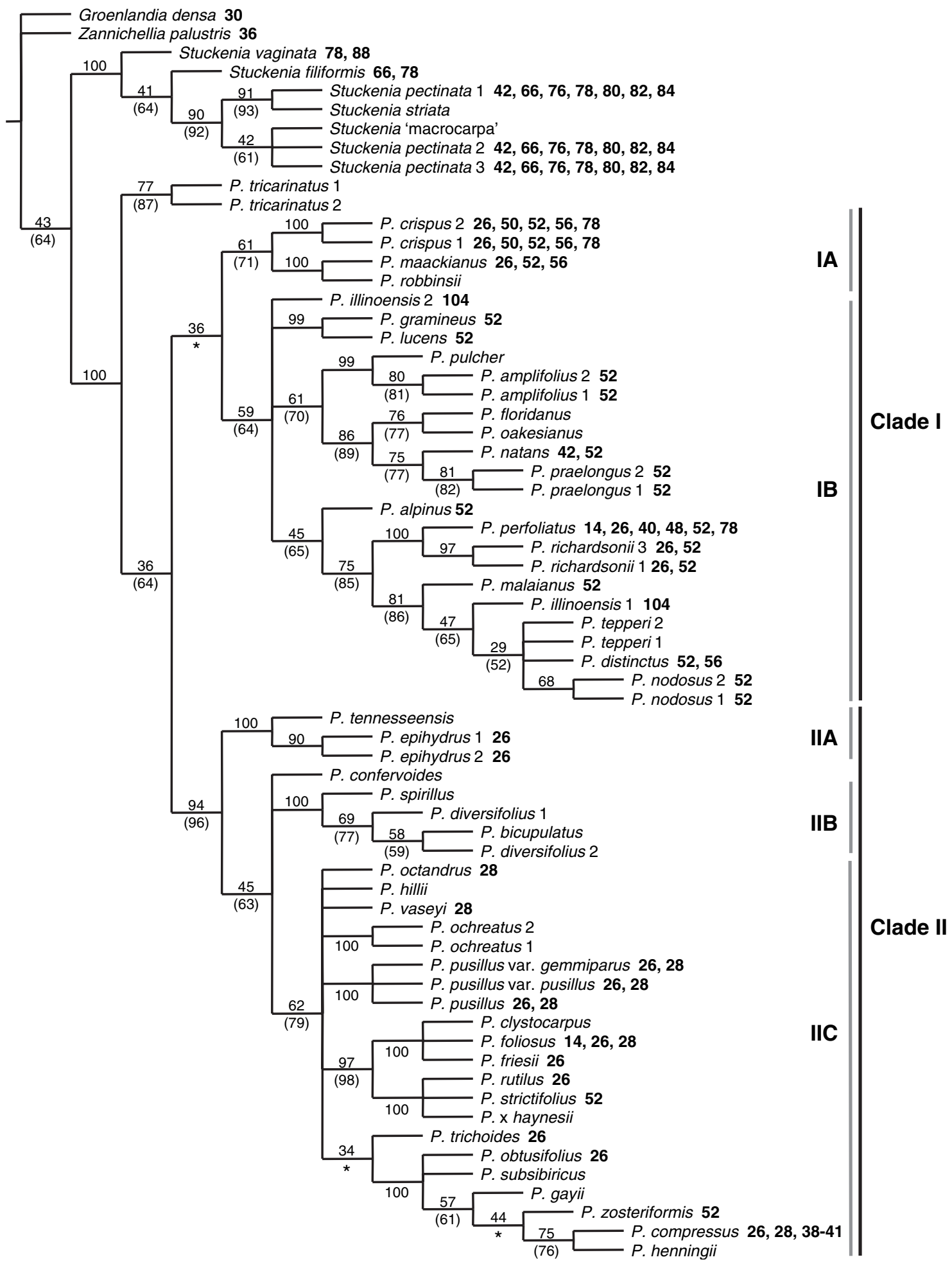

Fig. 2. 5S-NTS frequency difference jackknife consensus tree. Frequency difference jackknife support values shown above branches, and majority rule jackknife support values shown in parentheses below branches if different from frequency difference tree $\left({ }^{*}\right.$ node collapsed in majority rule tree). Chromosome numbers (2n) indicated in bold next to taxon name. 
(i.e., represented either an "orphan" $\operatorname{trn} L$ intron or psbA-trnH spacer sequence). The majority rule and frequency difference jackknife trees were highly congruent in topology with only minor differences (Fig. 1; see Methods for an explanation of the two different approaches). In both the majority rule and frequency difference jackknife trees, Potamogetonaceae plus Zannichellia constituted a strongly supported, monophyletic clade, and Potamogetonaceae itself was supported as a monophyletic group at $60 \%$ and $42 \%$, respectively (Fig. 1). Within Potamogetonaceae, the four Stuckenia taxa included were strongly supported as a monophyletic group. However, the relationship of this group and the single Groenlandia accession to the remaining taxa of Potamogetonaceae was unresolved. Nevertheless, several well-supported subclades within Potamogeton were recognized (see Fig. 1), e.g., (1) P. illinoensis, P. lucens, and P. nodosus, and (2) P. floridanus, P. oakesianus, $P$. amplifolius, $P$. nodosus and $P$. pulcher.

\section{Phylogenetic analyses of $5 S-N T S$ data}

The 5S-NTS sequence data matrix comprised 66 accessions. The 5S-NTS jackknife trees were far better resolved than the cpDNA trees (Fig. 2). Potamogeton constituted a well-supported, monophyletic clade sister to Stuckenia. Within Potamogeton, P. tricarinatus was supported as sister to the remaining taxa, which largely grouped into two separate clades I and II, although clade I was not supported in the majority rule jackknife tree and only marginally supported in the frequency difference tree. Clade I comprised two well-supported clades: one that included P. crispus, P. maackianus, and $P$. robbinsii (clade IA) and one that included predominantly "broad-leaved" taxa, e.g., P. illinoensis, $P$. lucens, and $P$. nodosus (clade IB). Clade II comprised a basal clade of $P$. tennesseensis and $P$. epihydrus (clade IIA) sister to a clade consisting of: (1) P. confervoides; (2) a clade of $P$. spirillus and allies (clade IIB); and (3) a clade of largely $P$. pusillus and allies, and $P$. compressus and allies (clade IIC).

\section{Phylogenetic analyses of all data combined}

The matrix of all data combined comprised 80 accessions. As with the chloroplast data combined, in the "total (available) evidence" results Potamogetonaceae plus Zannichellia constituted a strongly supported, monophyletic clade (Fig. 3). However, several differences in tree topology were found among the analyses of combined data versus the analyses of the chloroplast and nuclear DNA data alone. In the majority rule jackknife tree, Groenlandia was found to be sister to a poorly supported $(51 \%)$ clade of Zannichellia plus Stuckenia and Potamogeton, and Zannichellia in turn was supported as sister to Stuckenia and Potamogeton.
In the frequency difference jackknife tree, Groenlandia and Zannichellia were collapsed and weakly supported as sister to Stuckenia plus Potamogeton (see Fig. 3). Also inside Potamogeton several differences were present between the 5S-NTS analysis alone and the analysis of combined data, of which the most notable were: (1) $P$. tricarinatus was found as sister to "clade I" instead of as sister to all other Potamogeton, and (2) clade IA in the 5S-NTS tree was embedded inside clade IB of the combined analysis.

\section{Discussion}

Circumscription of Potamogetonaceae and infrafamilial relationships

The definition of Potamogetonaceae has historically varied among different authors. The family has, e.g., included the genus Ruppia and has been variously combined with members of the Zosteraceae, Cymodoceaceae, Zannichelliaceae and Najadaceae (e.g., Haynes, 1978; Les and Haynes, 1995). However, more recently the family has been considered to consist of three genera, Potamogeton, Stuckenia and Groenlandia. Based on morphology, Potamogetonaceae can be separated from these other families by their perfect flowers, lack of spathe-like bracts, and in some species, the presence of turions. The major difference between Zannichelliaceae and Potamogetonaceae is that the former has an envelope around the inflorescence, a character that is absent in Potamogetonaceae. Both Ruppiaceae and Potamogetonaceae bear drupelets, but those of the Potamogetonaceae are sessile, whereas those of Ruppiaceae are stipitate. Based on DNA sequence data from the chloroplast gene $r b c L$, Les et al. (1993) found Potamogetonaceae to be closely related to Zosteraceae but not to Ruppiaceae, which was placed as the sister group to the marine Cymodoceaceae, nor to Najadaceae, which was more closely related to Hydrocharitaceae than to other families of the previously circumscribed Najadales. Expanding the sampling to include more Alismatidae taxa, Les et al. (1997) showed Potamogetonaceae, together with members of Zannichelliaceae, to be placed in a relatively derived position within the subclass in a strongly supported clade sister to Zosteraceae. However, the $r b c L$ sequences only provided poor phylogenetic resolution within this clade, and only 10 taxa of Potamogetonaceae were included.

Our phylogenetic results of both the chloroplast data only and all data combined (chloroplast and 5S-NTS) show Potamogetonaceae plus Zannichellia to be a strongly supported group (Figs 1 and 3). In turn, however, the relationship of this group to other outgroup taxa included remains unresolved. Also, hypotheses on the interrelationships of the genera within 


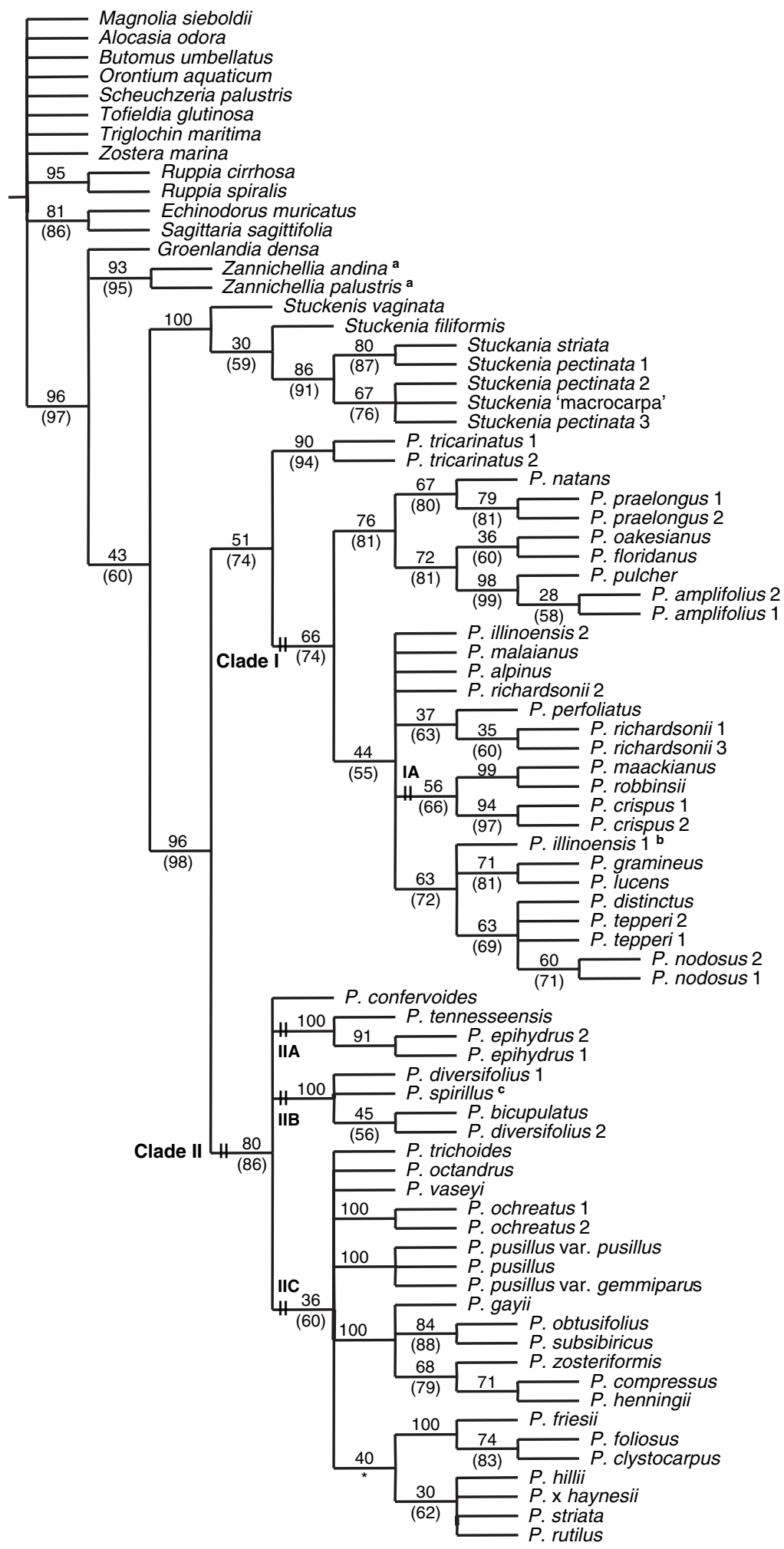

Fig. 3. Frequency difference jackknife consensus tree of 5S-NTS plus cpDNA combined. Frequency difference jackknife support values shown above branches, and majority rule jackknife support values shown in parentheses below branches if different from frequency difference tree ( ${ }^{a}$ the Zannichellia clade is supported at $51 \%$ as sister to Potamogeton plus Stuckenia in majority rule tree, ${ }^{\text {b }}$ supported at $54 \%$ as sister to P. distinctus clade, ${ }^{c}$ supported at $51 \%$ as sister to $P$. bicupulatus clade, ${ }^{*}$ node collapsed in majority rule tree). Bars on branches refer to clade names in the $5 \mathrm{~S}-\mathrm{NTS}$ tree (Fig. 2). 
this group are inconclusive. The cpDNA data alone show Zannichellia to be sister to the remaining taxa of Potamogetonaceae, whereas the chloroplast and nuclear DNA data combined show, while only poorly supported, Groenlandia either to be (1) sister to a clade of Zannichellia, which is in turn sister to Stuckenia plus Potamogeton (majority rule tree), or (2) unresolved with the Zannichellia clade as sister to the latter two genera (frequency difference tree). These inconsistencies between the regular and the frequency difference jackknife consensus trees are reflected in the low support values (see Fig. 3). Nevertheless, our data including considerably more Potamogetonaceae taxa as well as an additional Zannichellia accession still does not contradict the findings by Les et al. (1997) that Zannichellia(ceae) may be weakly embedded inside Potamogetonaceae. As a consequence of those findings the APG II system (Angiosperm Phylogeny Group, 2003) and Stevens (2004) included Zannichelliaceae within Potamogetonaceae. However, as none of the additional genera in Zannichelliaceae (Pseudalthenia (Graebn.) Nakai, Althenia Petit, and Lepilaena J.Drum. ex Harv.) were included here, our data may only support a transfer of Zannichellia alone.

Stuckenia-a separate genus?

Infrageneric classifications of Potamogeton have traditionally placed the species Potamogeton pectinatus and allies in separate units, either as a section (e.g., Coleophylli; Ascherson and Graebner, 1907) or subgenus (e.g., Coleogeton; Raunkiær, 1896), or more recently, as a species group (Wiegleb, 1988). Börner (1912) was the first author to propose this group as a separate genus, Stuckenia, although his endeavor was neglected by later works on Potamogeton taxonomy (Holub, 1997). Also Hagström (1916) recognized the separation of subgenus Coleogeton from subgenus Potamogeton and viewed it as occupying an isolated position within the genus (see also Les and Sheridan, 1990). More recently, several authors have attempted to elevate this group of taxa to generic level (Les and Haynes, 1996; Holub, 1997; Haynes et al., 1998). Among the main diagnostic features separating Stuckenia from Potamogeton s.str. (and Groenlandia) are long stipular sheaths, opaque submerged leaves, channeled and turgid flexible peduncles, and elongate stigmatic papillae (Les and Haynes, 1996; Holub, 1997). However, Wiegleb and Kaplan (1998) did not consider these characters as sufficient for distinguishing Stuckenia as a separate genus and adopted the traditional concept of treating the group at the rank of subgenus.

In our phylogenetic results based on nuclear and chloroplast plus nuclear data (Figs 2 and 3), all included Stuckenia species group into a strongly supported monophyletic clade sister to all included Potamogeton taxa, and therefore, corroborate the earlier view that this group of taxa represent a distinct lineage. Consequently, Stuckenia does not represent a highly specialized group derived from the Potamogeton pusillus group as proposed by Les and Sheridan (1990) but perhaps rather an ancestral lineage within Potamogeton s.l. as originally suggested by Hagström (1916; see also Les and Sheridan, 1990). As the Stuckenia and Potamogeton clades together form a monophyletic group, our results do not refute the inclusion of Stuckenia within the genus Potamogeton. However, we do argue for a continued recognition of the genus Stuckenia based on morphological, and anatomical as well as molecular data; these taxa clearly occupy an isolated position within Potamogetonaceae separate from Potamogeton sensu stricto.

\section{Infrageneric relationships and character evolution in Potamogeton}

Several attempts have been made to generate an infrageneric classification of Potamogeton, and species have been separated into either more formal sections and subsections or more informal groupings based on affinities (e.g., Raunkiær, 1903; Ascherson and Graebner, 1907; Hagström, 1916; Wiegleb, 1988). However, these groupings have often been criticized (see e.g., Les, 1983; Les and Sheridan, 1990), and in more recent taxonomic work on Potamogeton (Wiegleb and Kaplan, 1998), no infrageneric groupings were adopted but only notes on systematic affinities were included. Also, Haynes and Hellquist (2000) did not include an infrageneric classification in their treatment for the Flora of North America, as they believed that recognition of the many infrageneric categories was not of much utility. Taxonomic subdivision of Potamogeton is encumbered by the extensive phenotypic and genotypic variability, which may not only be expressed as a response to seasonal and environmental changes, but can also differ in different parts of the distributional range of a species (see e.g., Wiegleb, 1988; Kaplan, 2002).

Surprisingly, with our 5S-NTS sequence data we found Potamogeton tricarinatus to be supported as a sister taxon to the remaining Potamogeton (see Fig. 2). The epithet tricarinatus has been applied to almost any broad-leaved species of Potamogeton from Australia (Wiegleb and Kaplan, 1998), and it has been known for a long time that plants identified as $P$. tricarinatus include specimens that may represent a diversity of species (Papassotiriou, 1998). However, the two individuals included here, which were collected by Jacobs and Hellquist from Queensland and New South Wales and apparently represent a relatively rare plant (see Wiegleb and Kaplan, 1998), do indeed hold a very interesting position in Potamogeton, and obviously deserve species status. Wiegleb (1988) included $P$. tricarinatus in his "P. amplifolius group" but did 
question whether this taxon deserved a species status of its own. Unfortunately, it was not possible at this time to include $P$. tricarinatus in our cpDNA analyses, but in the combined data analyses this species was supported as sister to clade I (Fig. 3). Such incongruences are not unexpected giving the possible maternal inheritance of chloroplast DNA and presumed existence of hybridization within Potamogeton. Nevertheless, further studies of this interesting taxon are clearly needed. It may be that $P$. tricarinatus represents a relic taxon within Potamogeton.

None of the major taxonomic groups described in Wiegleb (1988) are found to be monophyletic in our analyses, although three small groups are supported as monophyletic: the monotypic "P. crispus" and " $P$. confervoides" groups as well as the " $P$. robbinsii group", which consist of $P$. maackianus and P. robbinsii, only. Other studies have pointed out the distinct positions these taxa hold in the genus. Most recently, a molecular phylogenetic study of Japanese Potamogeton (Iida et al., 2004) found P. crispus to be unique by having a long deletion and several autapomorphic substitutions in the trnT-trnL sequence. Also, allozyme analyses have shown this easily distinguished taxon to be distinct from other species in the genus (Hettiarachchi and Triest, 1991). Furthermore, studies of fruit characters have shown similarities between $P$. robbinsii and P. crispus (Aalto, 1974), which provide additional support to clade IA (Fig. 2). Potamogeton confervoides is regarded as an isolated species within Potamogeton (see e.g., Wiegleb and Kaplan, 1998).

Wiegleb (1988) combined Potamogeton perfoliatus and $P$. praelongus into his " $P$. perfoliatus group" (which also included $P$. richardsonii) although this group previously had been separated into two subsections (e.g., Raunkiær, 1903; Hagström, 1916). The members of these two subsections are the only species in the genus with clasping leaves. In addition to morphological features, the flavonoid chemistry support combining the two subsections into one (Haynes, 1985). However, in our phylogenetic analyses, the taxa of the two subsections are found in two different subclades of clade IB (Fig. 2), and therefore the data do not support combining the subsections. Instead, $P$. praelongus is supported as sister to $P$. natans (and is nested inside Wiegleb's " $P$. natans group" in the 5S-NTS analyses; Fig. 2). This latter relationship was also found by Iida et al. (2004). The close relationship of $P$. perfoliatus and $P$. richardsonii is supported here.

The species Potamogeton epihydrus, P. tennesseensis, $P$. bicupulatus, $P$. diversifolius, and $P$. spirillus have all been suggested to belong to one group, the "P. epihydrus group" (Wiegleb, 1988). In our study they are separated into two clades, which are not monophyletic with respect to each other (clade IIA and IIB, Fig. 2), although their interrelationship is unresolved in the combined analyses (see Fig. 3). In fact, clade IIA is found to be sister to all other taxa in clade II, which are all linear-leaved taxa (Fig. 2). Taxa in clades IIA and IIB are the only heterophyllous species (see also below) in clade II, apart from P. octandrus and $P$. vaseyi, which are very closely related taxa and polymorphic with respect to presence of floating leaves (see Fig. 4). Some of the morphological differences between clade IIA and IIB are that taxa in clade IIB have adnate stipules of the submerged leaves, di-trimorphic inflorescences, and the dorsal keel of the fruits is distinct. Members of clade IIB were also suggested by Wiegleb and Kaplan (1998) to be closely related. In fact, they noted that Potamogeton bicupulatus may be an extreme morphotype of $P$. diversifolius, and indeed in our 5S-NTS phylogenetic analyses we found this taxon to be nested inside P. diversifolius (Fig. 2).

Most of the members of our clade IIC (see Fig. 2) are members of the P. pusillus complex or subsection Pusilli Graebner. This clade is also the least resolved in our phylogenetic analyses. The $P$. pusillus complex has long been considered to be taxonomically difficult and uncertainty still exists as to the number of taxa that should be included (Haynes, 1974). Some of the reasons for the taxonomic confusion in this group may be that they are physically small and the morphological characters are therefore difficult to observe (Haynes, 1974). Moreover, they are extremely variable phenotypically, although this variation seems to be mostly environmentally induced (Kaplan, 2002). Haynes (1974) recognized 15 species in subsection Pusilli, and of these, eight North American species, including $P$. groenlandicus, were described and discussed. All eight species except $P$. groenlandicus are included in the present study. Haynes's (1974) phylogenetic hypothesis is not supported here, as he suggested that $P$. friesii and $P$. strictifolius represent ancestral Pusilli from which two main lines have evolved: (1) those taxa with dorsal and lateral keels absent ( $P$. pusillus and P. groenlandicus), and (2) those with dorsal and/or lateral keel present (P. obtusifolius, $P$. hillii, $P$. clystocarpus and $P$. foliosus). In our present analyses: (1) P. friesii is found to be closely related to P. clystocarpus and P. foliosus; (2) P. obtusifolius is strongly supported as belonging to a subclade including taxa of the "P. compressus group" (sensu Wiegleb, 1988; see also Wiegleb and Kaplan, 1998); and (3) P. hillii is unresolved within clade IIC (see Fig. 2). Wiegleb and Kaplan (1998) noted that P. obtusifolius is the most distinct species in the $P$. pusillus group.

A general trend from our phylogenetic results, when more than one accession of a species has been included, is that they are either exclusive lineages or group together (unresolved) within a particular clade. One exception is $P$. illinoensis, and clearly more work is needed on the $P$. illinoensis group, which also includes $P$. lucens and $P$. malaianus. 


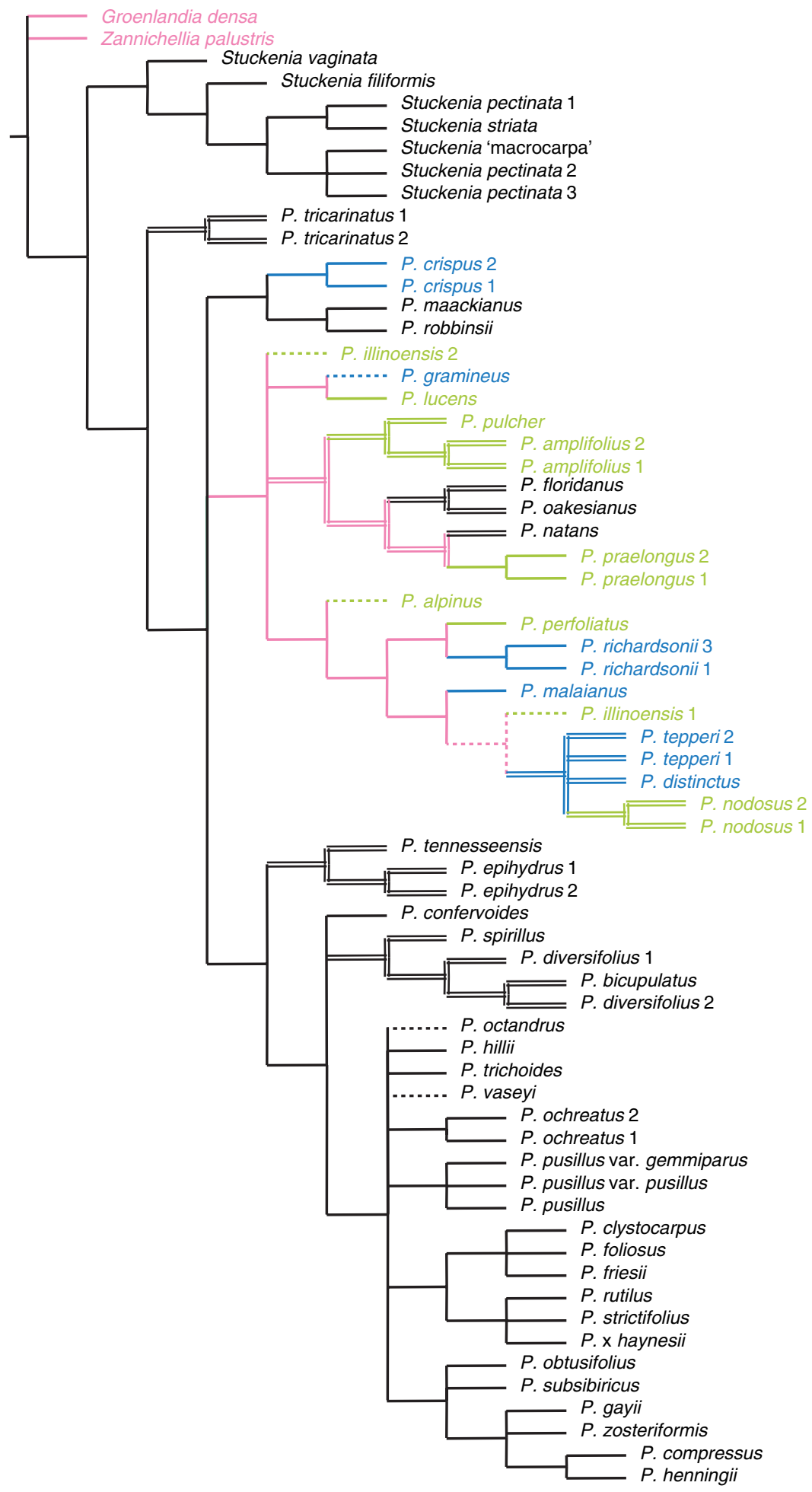

Fig. 4. Leaf width and heterophylly. 5S-NTS jackknife majority rule tree with maximum submerged leaf width and heterophylly unambiguously optimized. Leaf width optimization colors: black $=<15 \mathrm{~mm}$, blue $=16-25 \mathrm{~mm}$, green $=>30 \mathrm{~mm}$, pink $=$ ambiguity. Optimization of heterophylly: solid line $=$ absence and open line $=$ presence of floating leaves, dotted line $=$ polymorphic. 


\section{Leaf evolution}

Like many other aquatic plants, several Potamogeton species are characterized by heterophylly. In Potamogeton, the heterophyllous taxa typically exhibit much broader, coriaceous floating leaves in addition to the translucent, membranous, narrower submerged leaves. Several authors have speculated on the evolutionary relationships of heterophyllous and homophyllous species (e.g., Raunkiær, 1903; Hagström, 1916; Wiegleb, 1988; Les and Sheridan, 1990; see also below). When we optimized presence of floating leaves on to our 5S-NTS phylogenetic result, homophylly was clearly the ancestral state in Potamogeton (see Fig. 4). As a consequence, heterophylly has evolved several times in different lineages in the genus by parallel evolution. This trend supports the molecular phylogenetic results obtained from Japanese Potamogeton species (Iida et al., 2004).

Conveniently, two morphological groups in Potamogeton have been recognized, the "broad-leaved" species and the "linear-leaved" species, referring to the width of the submerged leaves (Fernald, 1932; Ogden, 1943), although it has been questioned if these groupings represent natural (monophyletic) entities (Les, 1983). In our molecular phylogenetic results with 5S-NTS nuclear DNA sequence data, the Potamogeton taxa grouped largely into a "broad-leaved" lineage (Clade I, Fig. 2) versus a "linear-leaved" lineage (Clade II, Fig. 2). Optimization of the maximum widths of the submerged leaves on to the 5S-NTS majority rule jackknife consensus tree (Fig. 4) indicated that the ancestral state in Potamogeton is leaves less than $15 \mathrm{~mm}$ broad, that the evolution of broader leaves has happened at least once, and at least one reversal back to more narrow leaves has occurred in Clade IB (P. floridanus, P. oaksianus, and
$P$. natans, although the submerged leaf lamina of the latter is considered to be reduced to linear phyllodes). The maximum recorded leaf width (according to Wiegleb and Kaplan, 1998 and own observations) was used rather than the more spurious terms "broad" and "narrow". The findings by Iida et al. (2004) showed a similar pattern, although $P$. natans and the broad-leaved $P$. praelongus were found in their Group II, which otherwise constituted the linear-leaved taxa. The maximum widths of the submerged leaves of the included taxa in our study shows that there is a curvilinear continuum from the most narrow to the broadest recorded width (see Fig. 5), although the broader leaves (e.g., width $>30 \mathrm{~mm}$ ) exhibit a greater heterogeneity in minimum and maximum recorded width.

Evolutionary hypotheses on the origin of homophyllous versus heterophyllous and linear-leaved versus broad-leaved Potamogeton have been discussed frequently by several authors (e.g., Raunkiær, 1903; Hagström, 1916; Wiegleb, 1988; Les and Sheridan, 1990). For example, Raunkiær (1903) hypothesized that heterophylly evolved from homophyllous, broad-leaved species as a consequence of adaptation to the aquatic habitat, whereas Hagström (1916) suggested that the genus arose from homophyllous, linear-leaved ancestors. More recently it has been argued that homophyllous, linearleaved species arose from heterophyllous Potamogeton (e.g., Les, 1983; Wiegleb, 1988). With our molecular phylogenetic findings, an ancestral state in Potamogeton is indicated as being homophyllous with linear leaves. Broad, submerged leaves have evolved at least once in Potamogeton, whereas heterophylly has arisen several times in parallel within the genus (Fig. 4). It has been shown that in a number of aquatic plants, exogenous

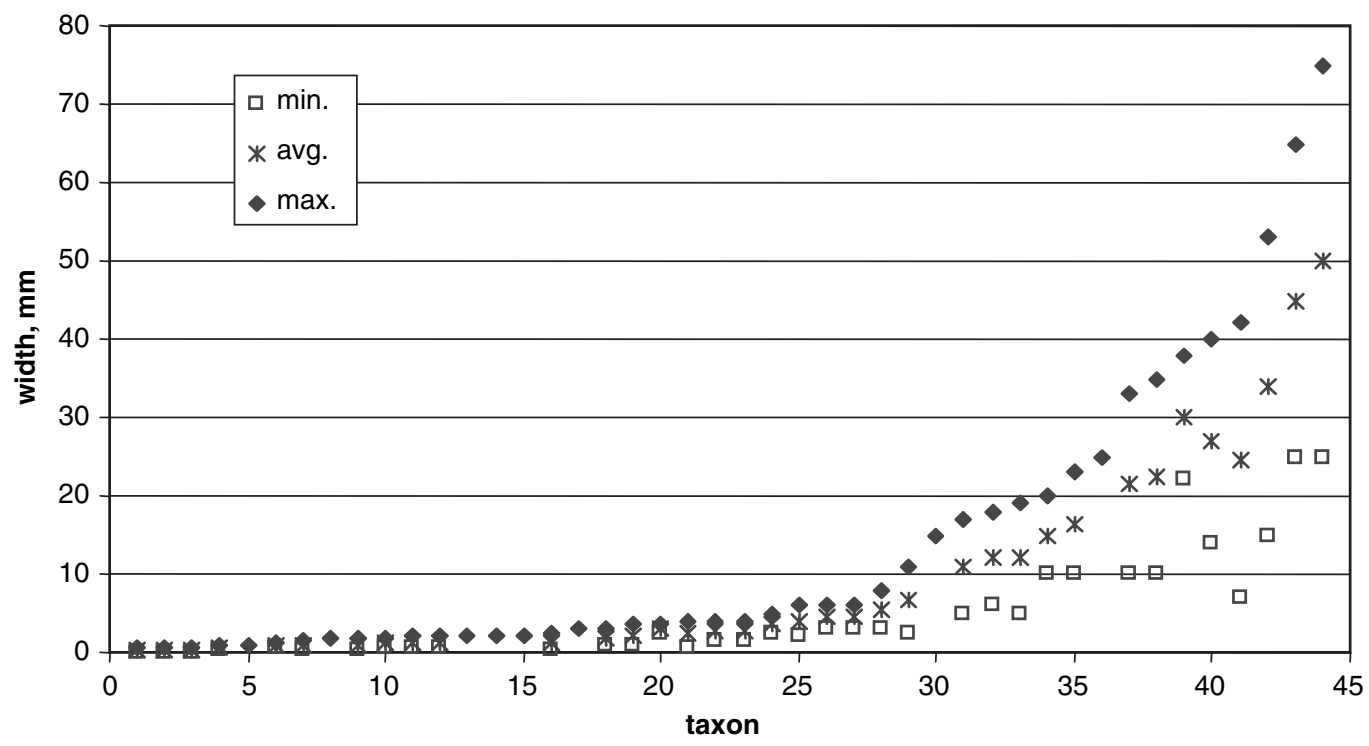

Fig. 5. Widths (maximum, minimum, and calculated average) of the submerged leaves plotted for each Potamogeton taxon included in the present study. Measurements according to Wiegleb and Kaplan (1998) and own observations. 
application of the plant hormone abscisic acid (ABA) triggers a phase change to heterophylly during the adult vegetative stage, and that $\mathrm{ABA}$ in these plants induces the formation of aerial-type morphology that is distinct from its counterpart submersed in water, particularly in the size and shape of the leaf (e.g., Lin, 2002). This ABA effect has been seen in phylogenetically derived taxa, including Potamogeton nodosus (Anderson, 1978). Thus, the genetic mechanism responsible for heterophylly may be easily triggered and could explain the repeated derivation of this trait in Potamogeton.

\section{Chromosomal evolution}

The chromosome numbers in Potamogeton sensu lato (i.e., including Stuckenia) exhibit extensive variation, not only between species, but also within many species. In Stuckenia, which in general show high ploidy levels and considerable aneuploidy, at least seven different numbers have been counted for S. pectinata (see Fig. 2). Also within Potamogeton, large chromosomal variability seems evident, with two chromosomal series present, one based on $x=7$ and the other on $x=13$. Several investigators have speculated as to chromosomal evolution and its correlation with Potamogeton taxonomy (see e.g., Les, 1983). However, varying classification, incorrect plant identification, technical difficulties in counting the small chromosomes, and use of misleading sources of chromosome counts are just some of the potential problems in this kind of endeavor. As a consequence of the latter, Hollingsworth et al. (1998) published a review of chromosome numbers in Potamogeton s.l. as an attempt to sort out previous errors and confusion in the literature. Although this review does not necessarily solve the three first issues, we have relied on their review here and used it in our interpretations based on our phylogenetic results. Of the total number of species, for which chromosome counts are reported in Hollingsworth et al. (1998), over 70\% (29 of 41 species) are represented in the present study. Of these, Potamogeton is represented by 26 species. Most of the ploidal and aneuploidal variation exists within our clade I (see Fig. 2), as both chromosomal series and ploidy levels from $2 n=14$ ( $P$. perfoliatus) to $2 n=104$ ( $P$. illinoensis) are found here. In addition, most of the intraspecific variation is found here, particularly represented by the species $P$. crispus and $P$. perfoliatus. In clade II, lower ploidy levels are evident, and it is only here that taxa with chromosome number $2 n=28$ are found. Consequently, species with floating leaves in clade I have for the most part $2 n=52$ or higher ( $P$. natans being the only exception with $2 n=42$ as well as $2 n=52$ ), whereas in clade II, species with floating leaves apparently have lower ploidy levels, i.e., $2 n=26$ or $2 n=28$. Within clade I and II no clear pattern is evident, and neither chromosome numbers nor base numbers seem to assemble into monophyletic groups in our phylogenetic tree. Furthermore, a correlation between morphology and chromosome/base number has previously been hypothesized, but our study corroborate the earlier observation (see Les, 1983; Les and Sheridan, 1990; Hollingsworth et al., 1998) that many of the suggested morphological groups are not homogeneous with respect to base chromosome number.

In reference to the apparent widespread occurrence of aneuploidy in Potamogeton (even when omitting Stuckenia) it has been proposed that $x=7$ represents the ancestral base number and that $x=13$ species arose from multiple origins through aneuploidy ("multiple origin hypothesis"; see Les, 1983; Les and Sheridan, 1990). The presence of $x=7$ numbers in almost all the taxa exhibiting chromosomal variation seems to support this hypothesis (see Les and Sheridan, 1990). However, if the two different chromosomal series $(x=7$ and $x=13)$ are mapped on to our phylogenetic tree, $x=13$ is optimized as the basal number (not shown), as was suggested by Wiegleb (1988). Other members in Potamogetonaceae and close relatives exhibit the numbers $n=6$ (Zannichellia), $n=15$ (Groenlandia), and in the sister group to Potamogetonaceae, Zostera, $n=6$ has been reported. It is important to note here that many Potamogeton taxa exhibit "missing" data (with either no counts reported, or counts suspicious and therefore excluded). Whether $x=$ 7 or $x=13$ represents the base number in Potamogeton does not entirely explain the extensive chromosomal variation and existence of both series within many species. It seems evident that the dynamics of chromosomal evolution in Potamogeton bear further study.

\section{Biogeographical inferences}

It has long been known that aquatic angiosperms, in general, have a wider distribution than their terrestrial relatives and that their remarkably wide distribution has caused great difficulties in speculations on their geographic origins (e.g., Arber, 1920; see also Les et al., 2003). Potamogeton is no exception, and in fact, not only are several species found throughout the Northern Hemisphere or found on numerous continents, but some species are even near-cosmopolitan (e.g., P. nodosus and $P$. perfoliatus; see also Fig. 7). Nevertheless, we will here attempt to infer some distributional trends based on our results.

When the actual geographic localities of the individual accessions used in this study are optimized on to the 5S-NTS tree, the ancestral geographic area for Potamogeton (plus Stuckenia) is North America (Fig. 6). In order to account for the predominant sampling of North American populations for this study, we also optimized the entire geographic distributions known for each species represented by the accessions, and again, North America was most-parsimoniously interpreted as the ancestral area (see Fig. 7). Based on fossil evidence, it 


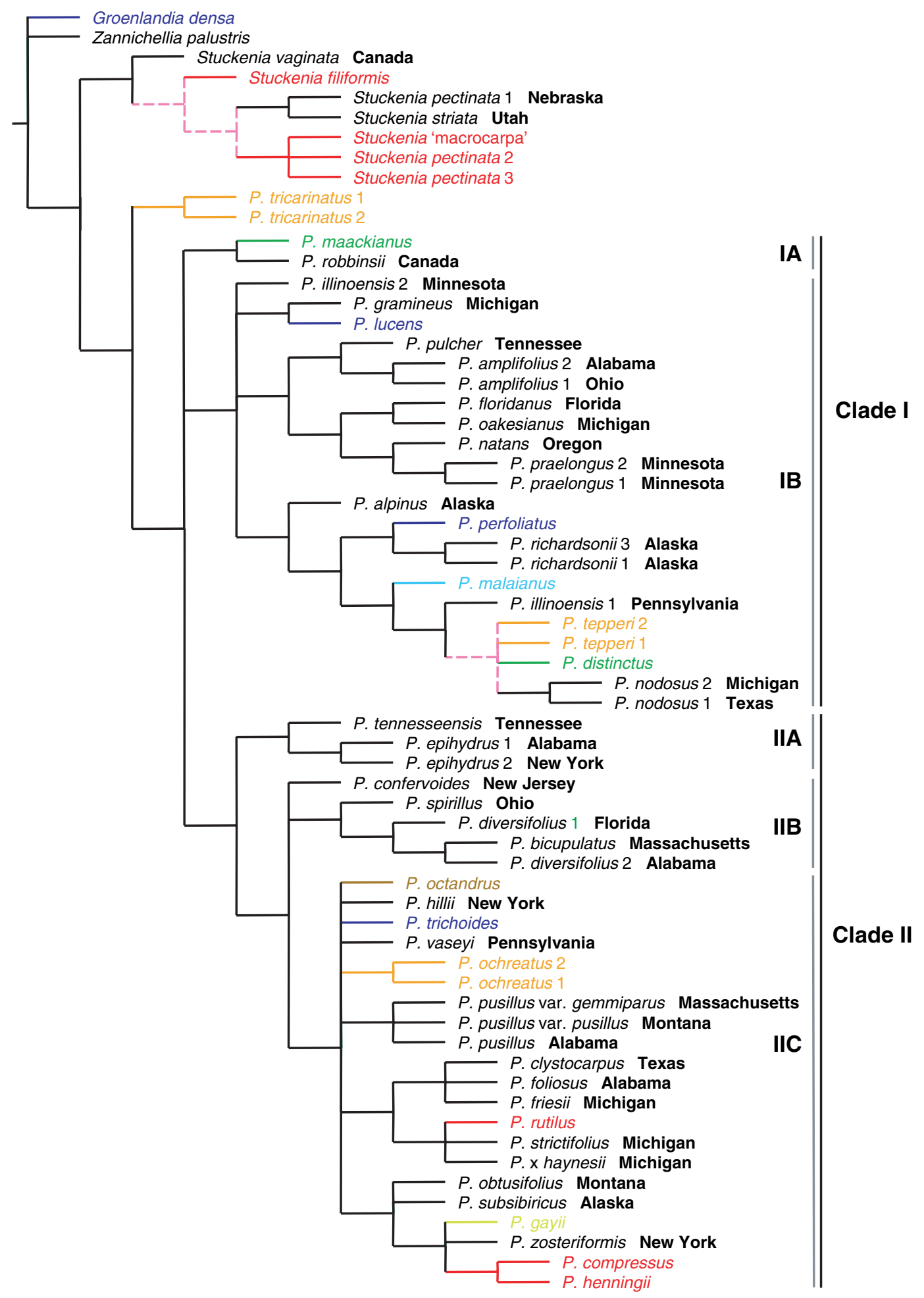

Fig. 6. Biogeography I. 5S-NTS jackknife majority rule tree with geographic collection locality of each accession unambiguously optimized (for North American taxa, the country or specific US state is indicated in bold after the taxon name; see also Table 1). Optimization colors: black $=$ North America, light green $=$ South America, blue $=$ Europe, red $=$ Siberia, green $=$ China, brown $=$ Africa, orange $=$ Australia, light blue $=$ Papua New Guinea, pink and stippled = ambiguity. Two accessions of Potamogeton crispus were omitted from the optimization analysis since they represent recent introductions to North America. Experiments with different coding schemes within the actual distribution of these accessions (see (Fig. 7) did not change the overall optimization of the Potamogeton lineage (not shown). 


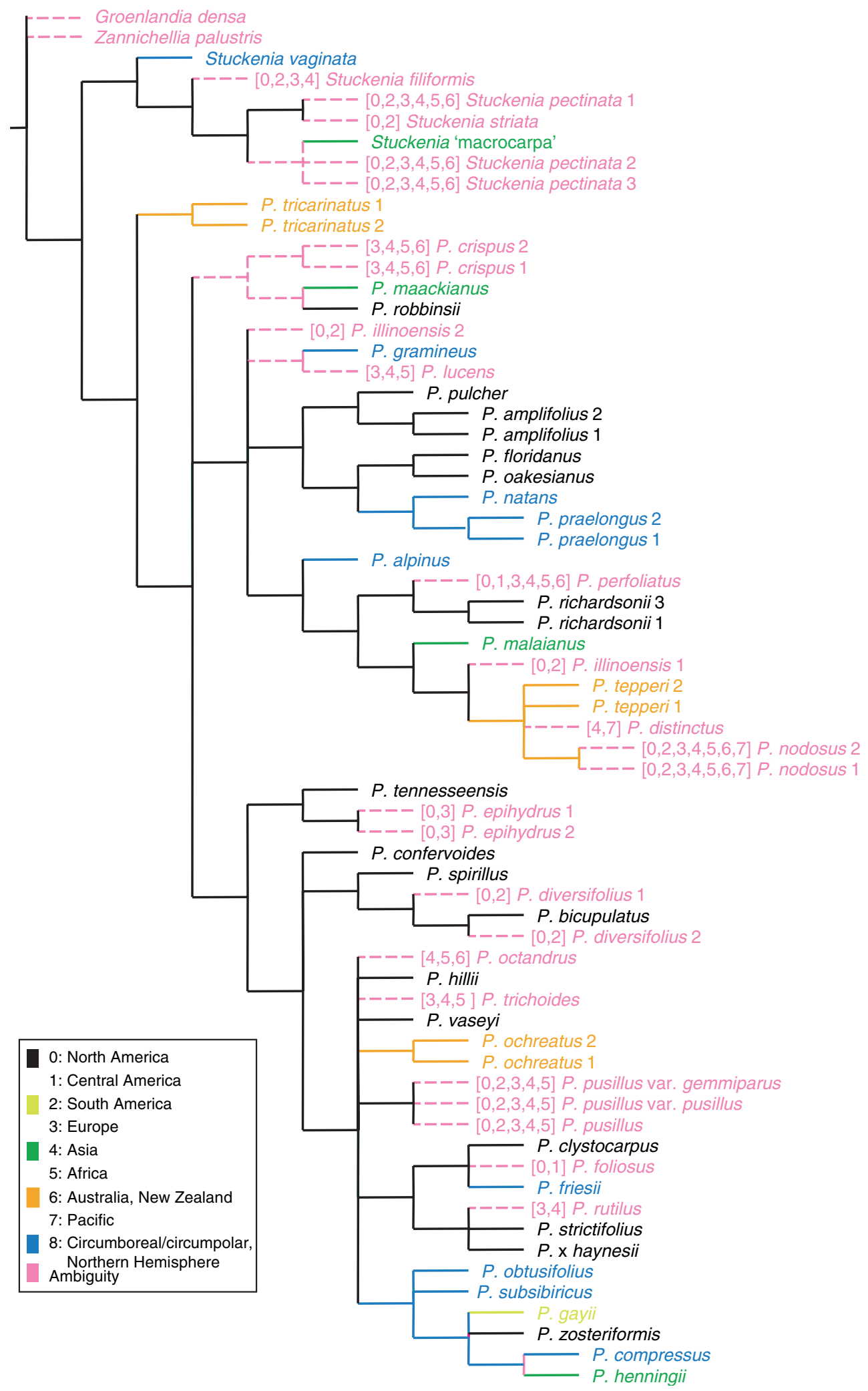

Fig. 7. Biogeography II. 5S-NTS jackknife majority rule tree with total geographic distribution area for each species unambiguously optimized. Colors on optimized tree: black $=$ North America, light green $=$ South America, green $=$ Asia, orange $=$ Australia and New Zealand, blue $=$ circumboreal/circumpolar/Northern Hemisphere, pink and stippled = ambiguity. 


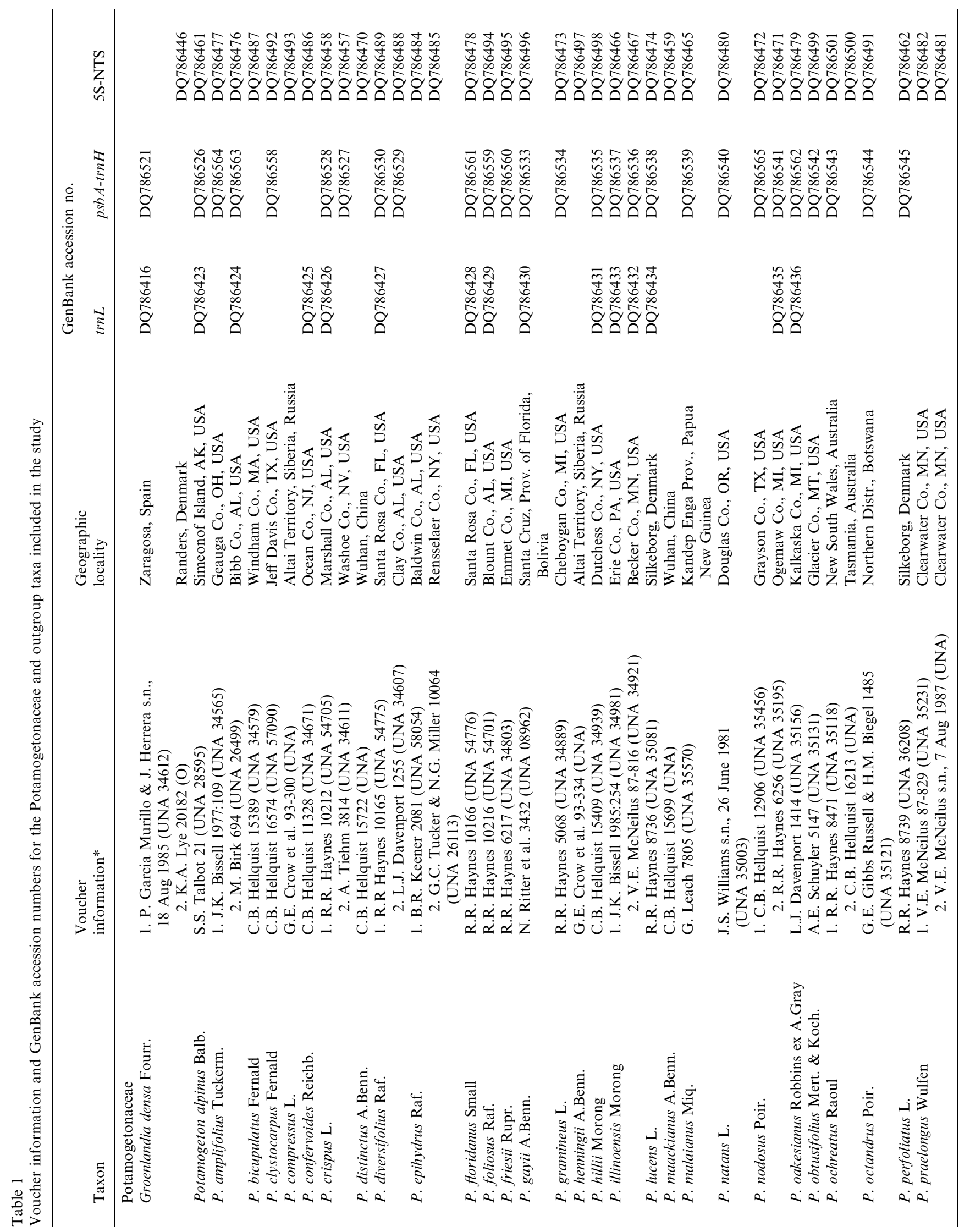




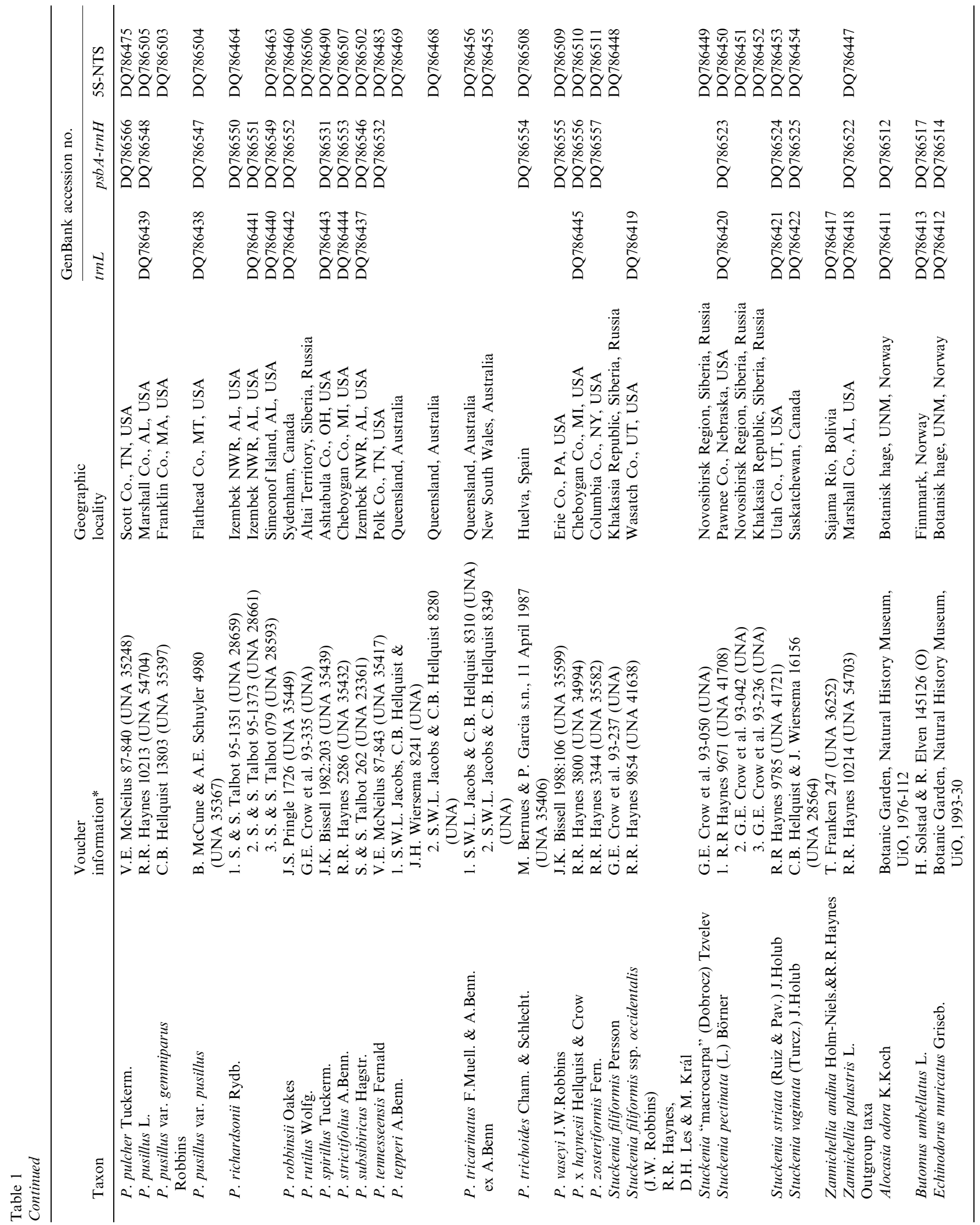




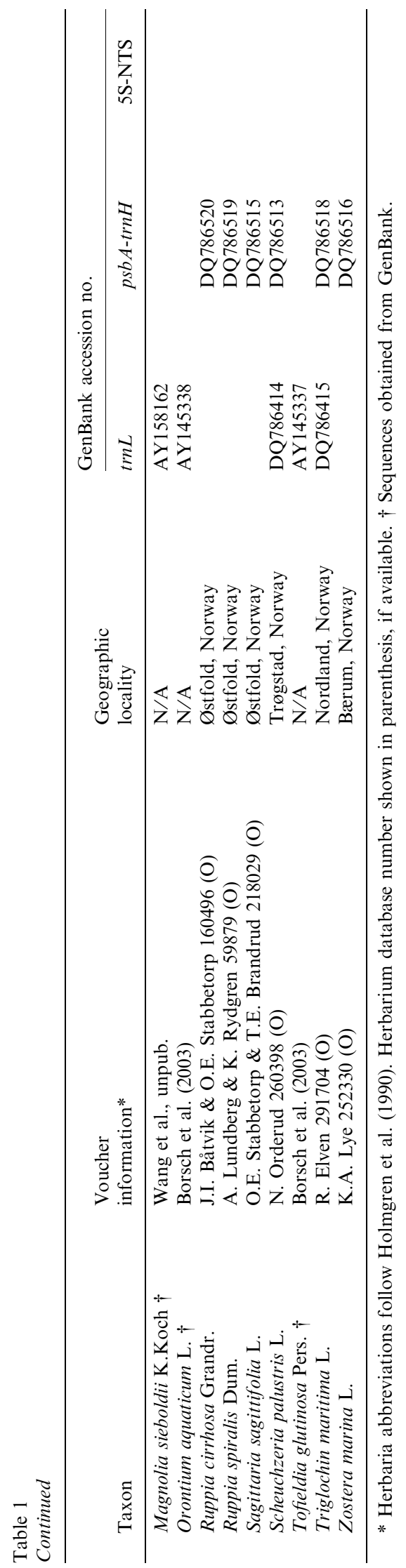

was previously suggested that Potamogeton (including Stuckenia) originated in East Asia (Miki, 1937). This suggestion was supported by Les (1983), who inferred an eastern Asian affinity based on the hypothesis of an $x=$ 7 ancestral base number. Although the position of Potamogeton tricarinatus, an Australian native, renders the ancestral origin of Potamogeton ambiguous if analyzed separately, i.e., excluding Stuckenia, it still seems likely that the entire lineage (Potamogeton plus Stuckenia) may have a North American origin. As many taxa in this lineage are also found in Eurasia or throughout the Northern Hemisphere, it is possible that a wider taxon and population sampling would expand the ancestral area to a general Northern Hemispheric distribution. This hypothesis can easily be supported by the presumed age of the lineage. Kato et al. (2003) suggested the divergence time between Potamogetonaceae and Zosteraceae to be approximately 100 million years (My). However, based on several reference fossils and comprehensive sampling of monocot taxa, Janssen and Bremer (2004) estimated the split between these two lineages to be less than $65 \mathrm{Myr}$ old and the stem node age of Potamogetonaceae to be 47 Myr old. An early Tertiary origin would coincide with the existence of the North Atlantic land bridge, which connected the floras of North America and Eurasia (e.g., Tiffney, 1985a). Eocene records of Potamogeton have been found in both Europe and North America (see Sculthorpe, 1967). If the diversity of species in particular geographic areas could be some indication of the geographic origin, a North American or Northern Hemisphere ancestry for Potamogeton is supported by the species densities in these areas. For example, Wiegleb (1988) divided the Potamogeton taxa into distribution types and found that the largest species group was North American. In fact, it has been noted that the highest density of species is found in a small area in the eastern portion of the USA and adjacent Canada. High species concentrations have also been reported from central and western USA, temperate Europe, north China and Japan (see Wiegleb, 1988).

Looking closer at the distributions of individual Potamogeton accessions mapped on to our phylogenetic tree, it is clear that the Potamogeton-Stuckenia lineage demonstrate a complex biogeographical history with suggestions of North American disjuncts, amphiatlantic and amphipacific patterns, and several migration events to the Southern Hemisphere (Fig. 6). However, these patterns may become obscured as more populations from throughout the distribution area of the widespread taxa were to be included. Nevertheless, based on our data, examples of possibly trans-Beringian disjuncts can be seen, e.g., in the Stuckenia clade and in clade IA of Potamogeton, where collects occupying (northern) Asian and North American localities show sister relationships. The connection between Asia and North America across 
Beringia remained a viable route for temperate-deciduous plant interchange through the Miocene and into the Quaternary (e.g., Hopkins, 1967; Tiffney, 1985a,b; Elias et al., 1996; Tiffney and Manchester, 2001). Particularly interesting are the Southern Hemisphere species, which are found in several places throughout the phylogenetic tree. For example, the three Australian taxa included ( $P$. tricarinatus, $P$. tepperi and $P$. ochreatus) are found within different, well-supported clades, of which $P$. tricarinatus holds the most basal position in the genus (also see above). Only one taxon each from South America (P. gayii) and Southern Africa (P. octandrus) are included in this study, both of which are found in clade IIC. Potamogeton malaianus from Papua New Guinea is sister to a clade of accessions otherwise from USA, China and Australia.

The ability of hydrophytes to expand such wide geographic ranges is intriguing, and it has been suggested that waterfowl are important agents in the longdistance dispersal of aquatic plants (e.g., Figuerola and Green, 2002; Santamaría and Klaassen, 2002; Les et al., 2003). Indeed, pondweeds have been considered to belong to the most valuable food source for ducks in the USA (see Haynes, 1974), and it is possible that ducks and other waterfowl are significant vectors of seed and plant dispersal across continents (see also Mader et al., 1998). However, other factors have also been suggested to account for the wide distribution of aquatic plants, e.g., clonal growth, plasticity and selection for stresstolerant taxa (see Barrett et al., 1993; Santamaría, 2002).

\section{Conclusions}

Aquatic plants are often characterized by extreme morphological reductions and extensive phenotypic plasticity, which have greatly challenged attempts of classical taxonomy and phylogenetic inference. Potamogeton is one of the most important plant genera in aquatic environments, yet until now, no comprehensive molecular phylogenetic study of this large genus has been published. We showed that the genera currently assigned to Potamogetonaceae, plus the genus Zannichellia (Zannichelliaceae), form a strongly supported monophyletic group and that Potamogeton and Stuckenia (Potamogeton subg. Coleogeton) are resolved as monophyletic sister clades. Within Potamogeton itself, two major clades largely follow the traditional split between broad- and narrow-leaved species, whereas heterophylly (submerged plus floating leaves) apparently evolved several times.

\section{Acknowledgments}

The authors thank the herbaria of the Universities of Alabama and Oslo and the Botanical Garden, Univer- sity of Oslo, for access to materials, Mika Bendiksby and Michelle Green for laboratory assistance, and Mika Bendiksby for comments. We also thank the College of Arts and Sciences, University of Alabama, the Botanical Garden, Natural History Museum, University of Oslo, and the Biological Diversity program of the Research Council of Norway (grant number 27741) for financial support of this research.

\section{References}

Aalto, M., 1974. Potamogetonaceae fruits. II. Potamogeton robbinsii, a seldom fruiting North American species. Ann. Bot. Fennici 11, 2933.

Anderson, L.W.J., 1978. Abscisic acid induces formation of floating leaves in the heterophyllous aquatic angiosperm Potamogeton nodosus. Science 201, 1135-1138.

Angiosperm Phylogeny Group, 2003. An update of the Angiosperm Phylogeny Group classification for the orders and families of flowering plants: APG II. Bot. J. Linnean Soc. 141, 399-436.

Arber, A., 1920. Water Plants: A Study of Aquatic Angiosperms. Cambridge University Press, Cambridge.

Ascherson, P., Graebner, P., 1907. Potamogetonaceae. In: Engler, A. (Ed.), Das Pflanzenreich: regni vegetabilis conspectus 31 (IV.11). Wilhelm Engelmann, Leipzig, pp. 1-183.

Barrett, S.C.H., Echert, C.G., Husband, B.C., 1993. Evolutionary processes in aquatic plant populations. Aquat Bot. 44, 105-145.

Börner, C., 1912. Botanisch-systematische Notizen. Abh. Naturwiss. Vereine Bremen 21, 245-282.

Borsch, T., Hilu, K.W., Quandt, D., Wilde, V., Neinhuis, C., Barthlott, W., 2003. Noncoding plastid trnT-trnF sequences reveal a well resolved phylogeny of basal angiosperms. J. Evol. Biol. 16, $558-576$.

Cook, C.D.K., 1990. Aquatic Plant Book. SPB Academic Publishing, The Hague.

Cox, A.V., Bennett, M.D., Dyer, T.A., 1992. Use of the polymerase chain reaction to detect spacer size heterogeneity in plant 5S-rRNA gene clusters and to locate such clusters in wheat (Triticum aestivum L.). Theor. Appl. Genet. 83, 684-690.

De Laet, J., 2005a. (G)oechel, Version 1.00. A POY shell to perform parsimony jackknife analysis of unaligned data. Distributed by the author at www.cladistics.com.

De Laet, J., 2005b. Parsimony and the problem of inapplicables in sequence data. In: Albert, V.A. (Ed.), Parsimony, Phylogeny, and Genomics. Oxford University Press, Oxford, pp. 81-116.

De Laet, J., Wheeler, W., 2003. POY, Version 3.0.11 (Wheeler, Gladstein and De Laet, 6 May 2003). Command line documentation. URL: http://research.amnh.org/scicomp/projects/poy.php

Dierberg, F.E., DeBusk, T.A., Jackson, S.D., Chimney, M.J., Pietro, K., 2002. Submerged aquatic vegetation-based treatment wetlands for removing phosphorus from agricultural runoff: response to hydraulic and nutrient loading. Water Res. 36, 1409-1422.

Elias, S.A., Short, S.K., Nelson, H., Birks, H.H., 1996. Life and times of the Bering land bridge. Nature 382, 60-63.

Fant, J.B., Kamau, E.M., Preston, C.D., 2003. Chloroplast evidence for the multiple origins of the hybrid Potamogeton $\times$ sudermanicus Hagstr. Aquat Bot. 75, 351-356.

Farris, J.S., Albert, V.A., Källersjö, M., Lipscomb, D., Kluge, A.G., 1996. Parsimony jackknifing outperforms neighbor-joining. Cladistics $12,99-124$.

Fernald, M.L., 1932. The linear-leaved North American species of Potamogeton section Axillares. Mem. Am. Acad. Arts N. Ser. 17, $1-183$. 
Figuerola, J., Green, A.J., 2002. Dispersal of aquatic organisms by waterbirds: a review of past research and priorities for future studies. Freshwater Biol. 47, 483-494.

Fritioff, A., Greger, M., 2003. Aquatic and terrestrial plant species with potential to remove heavy metals from storm-water. Int. J. Phytoremediation 5, 211-224.

Giannini, N.P., Simmons, N.B., 2005. Conflict and congruence in a combined DNA-morphology analysis of megachiropteran bat relationships (Mammalia: Chiroptera: Pteropodidae). Cladistics 21, 411-437.

Goloboff, P.A., 1999. Analyzing large datasets in reasonable times: solutions for composite optima. Cladistics 15, 415-428.

Goloboff, P.A., Farris, J.S., Nixon, K., 2002. TNT - Tree Analysis Using New Technology. Published by the authors.

Goloboff, P.A., Farris, J.S., Källersjö, M., Oxelman, B., Ramírez, M.J., Szumik, C.A., 2003. Improvements to resampling measures of group support. Cladistics 19, 324-332.

Hagström, J.O., 1916. Critical researches on the Potamogetons. Kungliga Svenska Vetenskapsakademiens Handlingar, 55, 1-281.

Haynes, R.R., 1974. A revision of North American Potamogeton subsection pusilli (Potamogetonceae). Rhodora, 76, 564-649.

Haynes, R.R., 1978. The Potamogetonaceae in the Southeastern United States. J. Arnold Arboretum, 59, 170-191.

Haynes, R.R., 1985. A revision of the clasping-leaved Potamogeton (Potamogetonaceae). SIDA, 11, 173-188.

Haynes, R.R., Hellquist, C.B., 2000. Potamogetonaceae Dumortier. Pondweed Family. In: F.O.N.A.E. Committee (Eds.), Flora of North America North of Mexico. 7+ Vols. Oxford University Press, New York and Oxford.

Haynes, R.R., Les, D.H., Král, M., 1998. Two new combinations in Stuckenia, the correct name for Coleogeton (Potamogetonaceae). Novon, 8, 241

Hettiarachchi, P., Triest, L., 1991. Isozyme polymorphism in the genus Potamogeton (Potamogetonaceae). In: Triest, L. (Ed.), Isozymes in Water Plants. Opera Botanica Belgica, 4. National Botanic Garden of Belgium, Meise, pp. 87-114.

Hollingsworth, P.M., Preston, C.D., Gornall, R.J., 1998. Euploid and aneuploid evolution in Potamogeton (Potamogetonaceae): a factual basis for interpretation. Aquat Bot. 60, 337-358.

Holmgren, P.K., Holmgren, N.H., Barrett, L.C., 1990. Index Herbariorum. Part I. The herbaria of the world. New York Botanical Garden Press, Bronx, New York.

Holub, J., 1997. Stuckenia Börner 1912: the correct name for Coleogeton (Potamogetonaceae). Preslia 69, 361-366.

Hopkins, D.M., 1967. The Bering Land Bridge. Stanford University Press California, Stanford, CA.

Iida, S., Kosuge, K., Kadono, Y., 2004. Molecular phylogeny of Japanese Potamogeton species in light of noncoding chloroplast sequences. Aquat Bot. 80, 115-127.

Janssen, T., Bremer, K., 2004. The age of major monocot groups inferred from $800+r b c L$ sequences. Bot. J. Linnean Soc. 146, 385-398.

Jiang, T.L., Lawler, E.L., 1994. Aligning sequences via an evolutionary tree: computational complexity and approximation. Proceedings of the 26th ACM Symposium on the Theory of Computing, 760-769.

Kaplan, Z., 2002. Phenotypic plasticity in Potamogeton (Potamogetonaceae). Folia Geobotanica 37, 141-170.

Kato, Y., Aioi, K., Omori, Y., Takahata, N., Satta, Y., 2003. Phylogenetic analyses of Zostera species based on rbcL and matK nucleotide sequences: implications for the origin and diversification of seagrasses in Japanese waters. Genes Genet. Syst. 78, 329-342.

Les, D.H., 1983. Taxonomic implications of aneuploidy and polyploidy in Potamogeton (Potamogetonaceae). Rhodora 85, 301-323.

Les, D.H., Haynes, R.R., 1995. Systematics of subclass Alismatidae. A synthesis of approaches. In: Rudall, P.J., Cribb, P.J., Cutler, D.F., Humphries, C.J. (Eds.), Monocotyledons: Systematics and Evolution. Royal Botanic Gardens, Kew, pp. 353-377.
Les, D.H., Haynes, R.R., 1996. Coleogeton (Potamogetonaceae), a new genus of pondweeds. Novon 6, 389-391.

Les, D.H., Sheridan, D.J., 1990. Hagström's concept of phylogenetic relationships in Potamogeton L. (Potamogetonaceae). Taxon 39, $41-58$.

Les, D.H., Garvin, D.K., Wimpee, C.F., 1993. Phylogenetic studies in the monocot subclass Alismatidae: evidence for a reappraisal of the aquatic order Najadales. Mol. Phylogenet. Evol. 2, 304-314.

Les, D.H., Cleland, M.A., Waycott, M., 1997. Phylogenetic studies in Alismatidae. II. Evolution of marine angiosperms (seagrasses) and hydrophily. Syst. Bot. 22, 443-463.

Les, D.H., Crawford, D.J., Kimball, R.T., Moody, M.L., Landolt, E., 2003. Biogeography of discontinuously distributed hydrophytes: a molecular appraisal of intercontinental disjunctions. Int. J. Plant Sci. 164, 917-932.

Lin, B.-L., 2002. Heterophylly in aquatic plants. http://www.plantphys. net. Essay 23.1.

Lindqvist, C., Albert, V.A., 2002. Origin of the Hawaiian endemic mints within North American Stachys (Lamiaceae). Am. J. Bot. 89, $1709-1724$.

Lindqvist, C., Motley, T.J., Jeffrey, J.J., Albert, V.A., 2003. Cladogenesis and reticulation in the Hawaiian endemic mints (Lamiaceae). Cladistics 19, 480-495.

Mader, E., van Vierssen, W., Schwenk, K., 1998. Clonal diversity in the submerged macrophyte Potamogeton pectinatus L. inferred from nuclear and cytoplasmic variation. Aquat Bot. 62, 147-160.

Miki, S., 1937. The origin of Najas and Potamogeton. Bot. Mag. 51, 472-481.

Nixon, K.C., 1999. The parsimony ratchet, a new method for rapid parsimony analysis. Cladistics 15, 407-414.

Nixon, K.C., 2002. Winclada, Version 1.00.08. Published by the author.

Ogden, E.C., 1943. The broad-leaved species of Potamogeton of North America north of Mexico. Rhodora 45, 57-241.

Papassotiriou, S.E., 1998. The taxonomy of the floating-leaved species of Potamogeton in Australia. In: Abstracts of: Monocots II: Second International Conference on the Comparative Biology of the Monocotyledons. URL: http://www.science.uts.edu.si/sasb/ monocotsIIAb2.html.

Raunkiær, C., 1896. De Danske Blomsterplanters Naturhistorie I. Helobieae, Copenhagen.

Raunkiær, C., 1903. Anatomical Potamogeton-studies and Potamogeton fluitans. Bot. Tidsskr. 25, 253-380.

Sang, T.D., Crawford, J., Stuessy, T.F., 1997. Chloroplast DNA phylogeny, reticulate evolution, and biogeography of Paeonia (Paeoniaceae). Am. J. Bot. 84, 1120-1120.

Sankoff, D., 1975. Minimal mutation trees of sequences. SIAM J. Appl. Math. 28, 35-42.

Santamaría, L., 2002. Why are most aquatic plants widely distributed? Dispersal, clonal growth and small-scale heterogeneity in a stressful environment. Acta Oecologica 23, 137-154.

Santamaría, L., Klaassen, M., 2002. Waterbird-mediated dispersal of aquatic organisms: an introduction. Acta Oecologica 23, 115-119.

Sculthorpe, C.D., 1967. The Biology of Aquatic Vascular Plants. Edward Arnold, London.

Stevens, P.F., 2004. Angiosperm Phylogeny Website, Version 5.

Taberlet, P., Gielly, L., Pautou, G., Bouvet, J., 1991. Universal primers for amplification of three non-coding regions of chloroplast DNA. Plant Mol. Biol. 17, 1105-1109.

Tiffney, B.H., 1985a. The Eocene North Atlantic land bridge: its importance in Tertiary and modern phytogeography of the Northern Hemisphere. J. Arnold Arboretum 66, 243-273.

Tiffney, B.H., 1985b. Perspectives in the origin of the floristic similarity between eastern Asia and eastern North America. J. Arnold Arboretum 66, 73-94.

Tiffney, B.H., Manchester, S.R., 2001. The use of geological and paleontological evidence in evaluating plant phylogeographic 
hypotheses in the Northern Hemisphere Tertiary. Int. J. Plant Sci. $162,3-17$.

Wheeler, W.C., 1996. Optimization alignment: the end of multiple sequence alignment in phylogenetics? Cladistics 12, 1-9.

Wheeler, W.C., 1999. Fixed character states and the optimization of molecular sequence data. Cladistics 15, 379-385.

Wheeler, W.C., 2003. Implied alignment: a synapomorphy-based multiple-sequence alignment method and its use in cladogram search. Cladistics, 19, 261-268.

Wheeler, W.C., 2005. Alignment, dynamic homology, and optimization. In: Albert, V.A. (Ed.), Parsimony, Phylogeny, and Genomics. Oxford University Press, Oxford, pp. 71-80.
Wheeler, W.C., Gladstein, D., De Laet, J., 2003. POY. Phylogeny Reconstruction Via Optimization of DNA and Other Data, Version 3.0.11.

Wiegleb, G., 1988. Notes on pondweeds: outlines for a monographical treatment of the genus Potamogeton L. Feddes Rep. 99, 249-266.

Wiegleb, G., Kaplan, Z., 1998. An account of the species of Potamogeton L. (Potamogetonaceae). Folia Geobotanica, 33, 241-316. 